CLINICAL STUDY

\title{
Preservation of GHRH and GH-releasing peptide-2 efficacy in young men with experimentally induced hypogonadism
}

\author{
Johannes D Veldhuis, Daniel M Keenan ${ }^{1}$, Joy N Bailey, John M Miles and Cyril Y Bowers ${ }^{2}$ \\ Endocrine Research Unit, Mayo School of Graduate Medical Education, Clinical Translational Science Center, Mayo Clinic, Rochester, Minnesota 55905, \\ USA, ${ }^{1}$ Department of Statistics, University of Virginia, Charlottesville, Virginia 22904, USA and ${ }^{2}$ Division of Endocrinology, Department of Internal \\ Medicine, Tulane University Health Sciences Center, New Orleans, Louisiana 70112, USA
}

(Correspondence should be addressed to J D Veldhuis; Email: veldhuis.johannes@mayo.edu)

\begin{abstract}
Background: Somatostatin (SS), GHRH, GH-releasing peptide (GHRP), and the sex-steroid milieu regulate $\mathrm{GH}$ secretion.

Objective: To test whether GHRH and GHRP remain effective secretagogs in the face of short-term hypogonadism.

Design: Prospective, randomized double-blind.

Methods: Healthy young men $(n=24)$ received a GnRH agonist twice 3 weeks apart followed by placebo $(n=13, \mathrm{Pl})$ or testosterone $(n=11$, testosterone) addback. Subjects were then given consecutive i.v. infusions of L-arginine (to restrain SS outflow) and a maximally effective dose of GHRH or GHRP-2 (to test corresponding secretagog pathways).

Results: GH secretion stimulated by L-arginine/GHRH and by L-arginine/GHRP-2 was unaffected by combined testosterone/estradiol $\left(\mathrm{E}_{2}\right)$ depletion. The low testosterone/ $\mathrm{E}_{2}$ milieu decreased basal (nonpulsatile) GH secretion $(P=0.038)$, without altering fasting pulsatile GH secretion or IGF1 or IGFbinding protein (IGFBP)-3 concentrations. IGFBP-1 $(P<0.0001)$ and abdominal visceral fat (AVF, $P=0.017)$ correlated negatively with fasting basal GH secretion. By contrast, IGF1 $(P=0.0012)$ and IGFBP-3 $(P=0.015)$ correlated positively with fasting pulsatile GH secretion. AVF $(P=0.0024)$ was a negative determinant, and IGF1 a positive determinant $(P=0.018)$, of GHRH-driven GH pulses. Responses to GHRP-2 were unrelated to any of these factors.

Conclusion: L-arginine/GHRP-2 appears to be an especially robust stimulus of GH secretion, since efficacy is unmodified by profound short-term hypogonadism, a range of AVF estimates, and a spectrum of IGF1, IGFBP-1, and IGFBP-3 concentrations. Whether robustness also applies to chronic hypogonadism is not known.
\end{abstract}

European Journal of Endocrinology $161293-300$

\section{Introduction}

$\mathrm{GH}$ is secreted predominantly in discrete bursts under the supervision of GH-releasing hormone (GHRH, a 40 and 44 amino acid peptide synthesized in the arcuate nucleus), GH-releasing peptide (GHRP, of which ghrelin is the endogenous 28 amino acid prototype produced in the hypothalamus, pituitary gland, and stomach), and somatostatin (SS; a 14 amino acid sequence made in the periventricular nucleus). Pulsatile GH secretion is also regulated strongly by sex-steroid hormones (1), which exert their stimulatory effects to a large degree via SS, GHRH, and GHRP (2). Testosterone and its aromatized product, estradiol $\left(\mathrm{E}_{2}\right)$, determine the amplitude and mass of $\mathrm{GH}$ pulses, whereas pathophysiological factors such as age, insulin-like growth factor (IGF) 1 feedback, and relative adiposity repress pulsatile GH secretion (3-5). In particular, administration of testosterone to prepubertal children and hypogonadal men enhances GH secretion after infusion of saline, L-arginine, or a maximally effective GHRP stimulus (6-9). On the other hand, the degree to which short-term testosterone or $\mathrm{E}_{2}$ deficiency affects combined secretagog actions in men is far less clear. Whereas two studies inferred that short-term pharmacological testosterone/ $\mathrm{E}_{2}$ deprivation does not diminish the efficacy of GHRH infused alone $(10,11)$, how acute hypogonadism affects combined L-arginine/GHRH or L-arginine/GHRP drive is not known. This point is important, as infusion of L-arginine before or with a peptidyl secretagog has been employed to restrict hypothalamic release of SS (12-15). The motivation for using L-arginine is to permit inferences about the efficacies of GHRH and GHRP in a low-SS milieu (2). Thus, the present study utilizes sequential L-arginine/GHRH versus L-arginine/ GHRP-2 infusions to examine their robustness to a 
low-testosterone/low-E $\mathrm{E}_{2}$ milieu in healthy men. Secondarily, we ask whether abdominal visceral fat (AVF) mass and prevailing markers of the IGF1 system influence combined-secretagog effects in this setting.

\section{Methods}

\section{Subjects}

Volunteers provided written informed consent approved by the Mayo Institutional Review Board and reviewed by the US Food and Drug Administration under investigator-initiated new drug numbers for GHRP-2 and GHRH. Exclusion criteria were exposure to psychotropic or neuroactive drugs within 1 year; body mass index (BMI) $<18$ and more than $32.5 \mathrm{~kg} / \mathrm{m}^{2}$; anemia (hemoglobin $<12.8 \mathrm{~g} / \mathrm{dl}$ ); drug or alcohol abuse, psychosis, depression, mania or severe anxiety; acute or chronic organ-system disease; use of testosterone, other anabolic steroids or glucocorticoids; endocrinopathy, other than primary thyroidal failure receiving replacement; nightshift work or recent transmeridian travel (exceeding three time zones within 7 days of study); acute weight change (loss or gain of $>2 \mathrm{~kg}$ in 6 weeks); allergy to administered peptides; and unwillingness to provide written informed consent. Each subject had an unremarkable medical history and physical examination and normal screening laboratory tests of hepatic, renal, endocrine, metabolic, and hematologic function. The men reported normal sexual development and function.

\section{Protocol}

The study design was parallel-cohort, double-blind, and prospectively randomized. Twenty-four healthy young men (age $24 \pm 0.72$ (s.e.M.) year, BMI $25 \pm 0.91 \mathrm{~kg} / \mathrm{m}^{2}$ ) received two consecutive i.m. injections of depot leuprolide acetate ( $3.75 \mathrm{mg}$ i.m. 3 weeks apart) to deplete systemic testosterone and $E_{2}$ concentrations. The synergy between GHRH and GHRP-2 in these subjects was presented earlier (16). Beginning on the day of the second leuprolide injection, volunteers were given either saline $(n=13)$ or a pharmacological dose of $200 \mathrm{mg}$ testosterone enanthate $(n=11)$ i.m. weekly for three doses (designated as days 0, 7, and 14) double-blind. Secretagog infusions were scheduled during the time window 10-18 days. Each participant was studied twice in the Clinical-Translational Research Unit (CRU) at least $48 \mathrm{~h}$ apart on separate mornings after a standardized evening meal and subsequent overnight fast.

Volunteers continued their usual level of daily physical activities, except the evening before and on the day of study. Subjects were admitted to the CRU before $1700 \mathrm{~h}$ and stayed overnight. Sleep was not monitored. Room lights were put out at $2230 \mathrm{~h}$. To limit nutritional confounds, a single constant meal (vegetarian or nonvegetarian) was given in the CRU at
$1800 \mathrm{~h}$ the night before study comprising $12 \mathrm{kcal} / \mathrm{kg}$ distributed as $50 \%$ carbohydrate, $20 \%$ protein, and $30 \%$ fat. Volunteers then remained fasting, alcoholabstinent, and caffeine-free overnight until the end of the infusion the next day.

In the CRU, catheters were placed in contralateral forearm veins at $0700 \mathrm{~h}$ to allow simultaneous infusion of secretagogs and blood sampling every $10 \mathrm{~min}$ for a total of $6 \mathrm{~h}$ beginning at $0800 \mathrm{~h}$. Sampling encompassed a 3-h baseline and 3-h stimulation interval. Infusions comprised L-arginine 30 gm delivered i.v. over $30 \mathrm{~min}$, followed immediately by i.v. bolus of either $1 \mu \mathrm{g} / \mathrm{kg}$ GHRH (GEREF; Serono) or $3 \mu \mathrm{g} / \mathrm{kg}$ GHRP-2 (Takeda Pharmaceuticals, Deerfield, IL, USA). The doses of L-arginine and both peptides are maximally stimulatory in adults $(17,18)$. L-Arginine was employed to antagonize central SS outflow $(12,13)$.

Blood was also withdrawn at $0800 \mathrm{~h}$ for later assay of serum $\mathrm{E}_{2}$, testosterone, LH, FSH, IGF1, IGF-binding protein (IGFBP)-1, IGFBP-3, albumin and SHBG concentrations. Lunch was provided after sampling before discharge from the CRU.

\section{Hormone assays}

Serum GH concentrations were determined in duplicate by automated ultrasensitive two-site immunoenzymatic chemiluminescence assay performed on the DxI automated system (Beckman Instruments, Chaska, MN, USA 55318). Interassay coefficient of variations (CVs) were $6.1 \%$ at $0.46 \mu \mathrm{g} / \mathrm{l}, 4.3 \%$ at $3.0 \mu \mathrm{g} / \mathrm{l}, 5.0 \%$ at $7.2 \mu \mathrm{g} / \mathrm{l}$, and $4.8 \%$ at $13.6 \mu \mathrm{g} / \mathrm{l}$. Intra-assay $\mathrm{CVs}$ were $4.7 \%$ at $0.37 \mu \mathrm{g} / \mathrm{l}, 3.5 \%$ at $2.5 \mu \mathrm{g} / \mathrm{l}$, and $3.2 \%$ at $14.8 \mu \mathrm{g} / \mathrm{l}$. The lowest detectable $\mathrm{GH}$ concentration at $95 \%$ confidence is $0.008 \mu \mathrm{g} / \mathrm{l}$ determined by processing a six-point calibration curve, five quality controls, and ten replicates of zero calibrator in multiple assays. The GH standard was recombinant human $22 \mathrm{kDa} G H$.

$\mathrm{E}_{2}$ and testosterone were measured by tandem liquidchromatography ion-spray mass spectrometry. For $\mathrm{E}_{2}$, intra-assay CVs were $18,3.8$, and $7.2 \%$ at concentrations of $3.6,40$, and $297 \mathrm{pg} / \mathrm{ml}$ (multiply by 3.68 for pmol/l). Interassay CVs were $8.1,4.7$, and $4.9 \%$ at 16 , 31 , and $119 \mathrm{pg} / \mathrm{ml}$ respectively. For testosterone, the analytic range is $7-2000 \mathrm{ng} / \mathrm{dl}$ (multiply by 0.0347 for $\mathrm{nmol} / \mathrm{l}$ ) for a $0.1 \mathrm{ml}$ volume. Intra-assay CVs were 3.3 , $2.8,2.2$, and $2.0 \%$ at testosterone concentrations of 16 , 64, 184, and $927 \mathrm{ng} / \mathrm{dl}$ respectively. Corresponding interassay CVs were $5.1,3.8,3.7$, and $2.8 \%$. Free and bioavailable testosterone concentrations were calculated as described earlier (19).

IGFBP-1, IGFBP-3, and total IGF1 concentrations were quantified by IRMAs (Diagnostic Systems Laboratories, Webster, TX, USA) as described (20). Intra- and interassay CVs were 6.1 and $8.4 \%$ for IGFBP-1, and 5.8 and $8.5 \%$ for IGFBP-3 respectively. Intra-assay CVs for IGF 1 were $3.4 \%$ at $9.4,3 \%$ at 55 , and $1.5 \%$ at $264 \mu \mathrm{g} / \mathrm{l}$, and interassay CVs $9 \%$ at $64 \mu \mathrm{g} / \mathrm{l}$ and $6.2 \%$ at $157 \mu \mathrm{g} / \mathrm{l}$. 

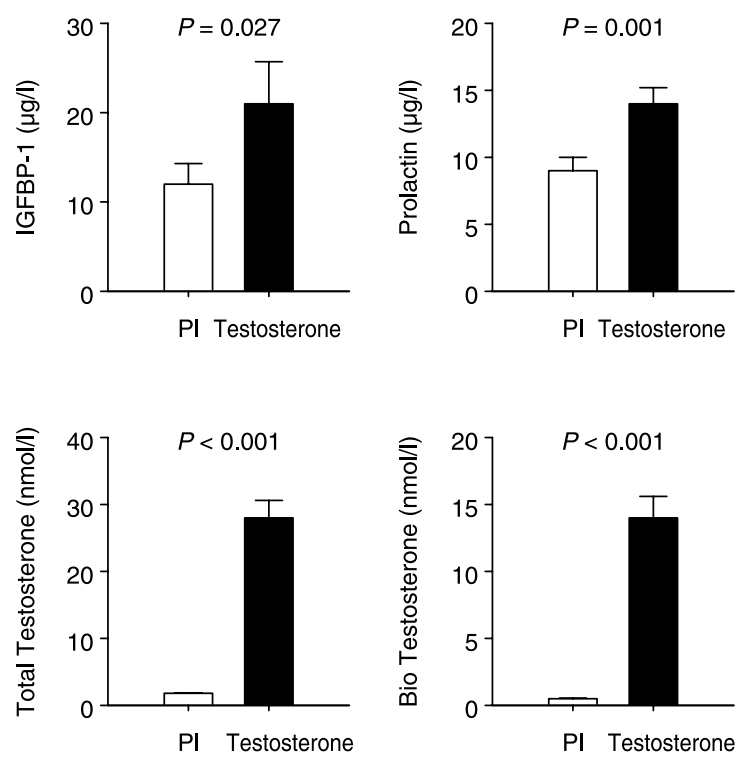

\section{Statistical analysis}

An unpaired Student's $t$-test was used to compare age, BMI, and AVF as well as baseline fasting hormone concentrations in the two groups. Two-way ANOVA $(2 \times 2$ factorial design) was used to examine the individual and interactive effects of normal versus low testosterone/ $\mathrm{E}_{2}$ (two factors) and secretagog type (two factors) on the summed mass of GH secreted in pulses over the $3 \mathrm{~h}$ after secretagog infusion. Post hoc contrasts were made via Fischer's least-significant difference test (21). Log transformation was used to limit the dispersion of residual variance. Linear regression analysis and Pearson's correlation-coefficient $P$ value were applied to examine the relationship between GH secretion and age, AVF, IGF1, IGFBP-1, and IGFBP-3 concentrations (Systat, Point Richmond, CA, USA). Bonferroni correction was applied to the three IGF-related measures $(P \leq 0.0167)$. Significant differences were corroborated by the nonparametric rank-sum and Kruskal-Wallis tests (21).

Data are presented as the mean \pm s.E.M. Experimentwise $P<0.05$ was construed as statistically significant.

\section{Statistical power analysis}

Data from 18 studies in hypogonadal or normal males $(n=149$ subjects total) indicate that parenteral testosterone supplementation increases mean $\mathrm{GH}$ concentrations by a weighted-mean effect size (SDS) of $1.8(6,8,9,11,22-26)$. Power analysis assumed that testosterone/ $\mathrm{E}_{2}$ depletion exerts an opposite effect of similar relative magnitude. If comparison is made via a one-tailed (based upon the prior hypothesis) unpaired Student's $t$-test at protected $P \leq 0.01$, then analysis of data from a total of 24 subjects ( $\sim 12$ in each group) would achieve $>99 \%$ power to detect this effect size.
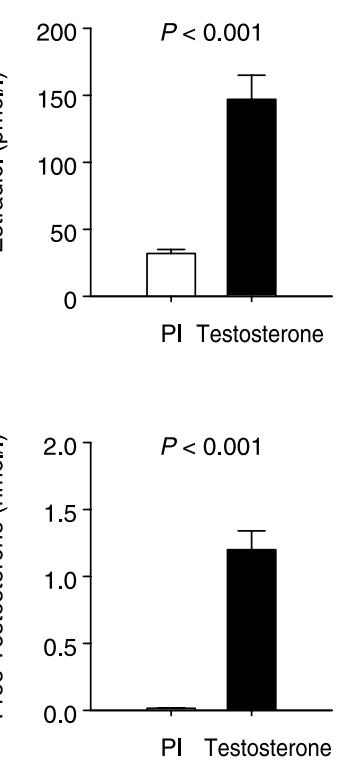

Figure 1 Significant hormonal differences in young men given leuprolide plus placebo versus leuprolide plus testosterone addback.

\section{Deconvolution analysis}

GH concentration time series were analyzed using a recently developed automated deconvolution method, which was verified mathematically by direct statistical proof and validated empirically by hypothalamopituitary sampling and simulated pulsatile time series $(27,28)$. The Matlab-based algorithm first detrends the data and normalizes concentrations to the unit interval $(0,1)$. Second, the program creates multiple sets of potential pulse times via an incremental smoothing process (a nonlinear adaptation of the heat-diffusion equation). Third, a maximum-likelihood estimation method calculates all secretion and elimination parameters for each of the multiple candidate pulsetime sets. Deconvolution parameters comprise basal secretion $\left(\beta_{0}\right)$, two half-lives $\left(\alpha_{1}, \alpha_{2}\right)$, secretory-burst

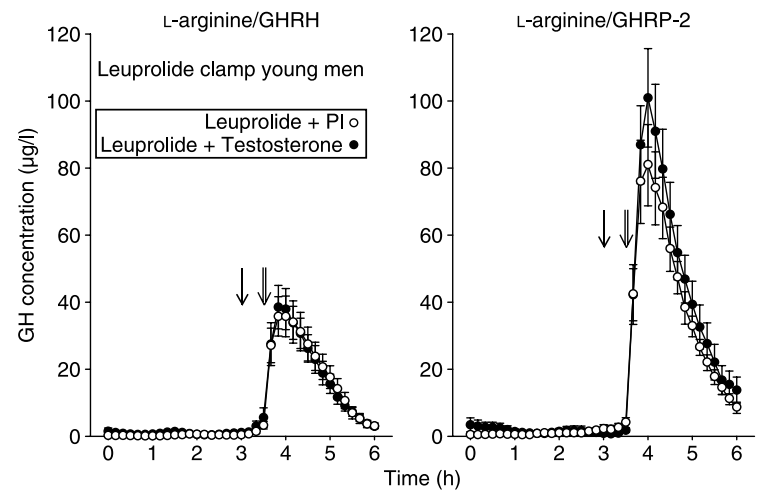

Figure 2 Time profiles of $\mathrm{GH}$ concentrations sampled every $10 \mathrm{~min}$ for $6 \mathrm{~h}$ fasting in 13 young men given leuprolide and placebo $(\mathrm{PI})$ and 11 others given leuprolide and testosterone injections. Saline was infused i.v. for $3 \mathrm{~h}$, then L-arginine for $0.5 \mathrm{~h}$ (single arrows) followed by bolus GHRH or GHRP-2 (double arrows). Data are the mean \pm S.E.M. 
Table 1 Impact of testosterone/estradiol $\left(\mathrm{E}_{2}\right)$ depletion versus repletion on $\mathrm{GH}$ secretion ${ }^{\mathrm{a}}$.

\begin{tabular}{lccc}
\hline Endpoint & Leuprolide \pm PI $(n=13)$ & Leuprolide \pm testosterone $(n=11)$ & $P$ value \\
\hline Basal (nonpulsatile) GH secretion & $2.3 \pm 0.52$ & $4.0 \pm 0.94$ & 0.019 \\
Unstimulated pulsatile GH secretion & $5.1 \pm 2.6$ & $4.9 \pm 1.6$ & $>0.10$ \\
L-arginine/GHRH stimulation & $117 \pm 19$ & $103 \pm 15$ & $>0.10$ \\
L-arginine/GHRP-2 stimulation & $235 \pm 27$ & $273 \pm 41$ & $>0.10$
\end{tabular}

Data are the mean \pm S.E.M. $P$ values were estimated by an unpaired one-tailed Student's $t$-test under the prior hypothesis that testosterone/ $E_{2}$ depletion lowers GH output.

aUnits are $\mu \mathrm{g} / \mathrm{l}$ per $3 \mathrm{~h}$.

mass $\left(\eta_{0}, \eta_{1}\right)$, random effects on burst mass $\left(\sigma_{\mathrm{A}}\right)$, procedural/measurement error $\left(\sigma_{\varepsilon}\right)$, and a threeparameter flexible Gamma-secretory-burst waveform $\left(\beta_{1}-\beta_{3}\right)$. The fast half-life of $\mathrm{GH}$ was represented as 3.5 min constituting $37 \%$ of the decay amplitude and the slow half-life as $20.8 \mathrm{~min}$ (29). The Akaike information criterion (30) is used to select the optimal pulse-time set from the multiple candidate sets. Other parameters are basal and pulsatile secretion rates (concentration units $/ 3 \mathrm{~h}$ ), mass secreted per burst (concentration units), and waveform mode (time delay to maximal secretion after burst onset).

\section{Visceral fat mass}

Intraabdominal visceral fat mass was estimated by single-slice abdominal CT scan at L3-L4, exactly as reported (4).

\section{Results}

As described earlier and in a Supplemental (Appendix) Table, which can be viewed online at http://www.ejeonline.org/supplemental/ baseline subject characteristics did not differ in volunteers assigned to the leuprolide/placebo $(\mathrm{Pl})$ and leuprolide/testosterone treatment groups (16). By contrast, post-leuprolide versus post-Pl hormone concentrations differed significantly with respect to: a) IGFBP-1 (higher in the testosterone addback group, $P=0.027$ ); b) prolactin (higher in the testosterone group, $P=0.001$ ); c) FSH (lower in the testosterone group, $P<0.001$ ); and d) $\mathrm{E}_{2}$, total testosterone, bioavailable testosterone, and free testosterone (each higher by $P<0.001$ in the testosterone group; Fig. 1). The data suggest that eugonadal testosterone concentrations contribute to maintaining IGFBP-1 and prolactin concentrations, and in suppressing FSH concentrations. IGF1, IGFBP-3, SHBG, and LH concentrations were similar in the $\mathrm{Pl}$ and testosterone cohorts after leuprolide injection, whereas FSH was lower after leuprolide plus testosterone $(0.35 \pm 0.11 \mathrm{IU} / \mathrm{l})$ than leuprolide plus $\mathrm{Pl}(2.3 \pm 0.43 \mathrm{IU} / \mathrm{l}, P=0.001)$. Therefore, testosterone potentiated suppression of FSH by leuprolide, without further affecting LH or SHBG. Moreover, IGF1 and IGFBP-3 were not affected.
Figure 2 presents $\mathrm{GH}$ concentrations (mean \pm s.E.M.) sampled every $10 \mathrm{~min}$ for $6 \mathrm{~h}$, comprising 3-h salineinfused and 3-h secretagog-stimulated profiles. Data were obtained after leuprolide injection plus $\mathrm{Pl}$ versus testosterone addback. The peak and time course of GH responses were comparable visually in the two cohorts. Unstimulated (pre-secretagog) mean GH concentrations were $0.61 \pm 0.19(\mathrm{Pl})$ and $1.3 \pm 0.49 \mu \mathrm{g} / \mathrm{l}$ (testosterone) $(P=0.046)$, and estimated basal (nonpulsatile) GH secretion rates were $2.3 \pm 0.52(\mathrm{Pl})$ versus $4.0 \pm 0.94 \mu \mathrm{g} / \mathrm{l}$ per $3 \mathrm{~h}$ (testosterone) $(P=0.038)$. Unstimulated fasting pulsatile $\mathrm{GH}$ secretion was not affected by the sex-steroid milieu $(P=0.37$; Table 1$)$. Thus, short-term testosterone depletion mainly reduced basal GH secretion. In relation to sequential secretagogstimulated GH release, two-way ANOVA identified a

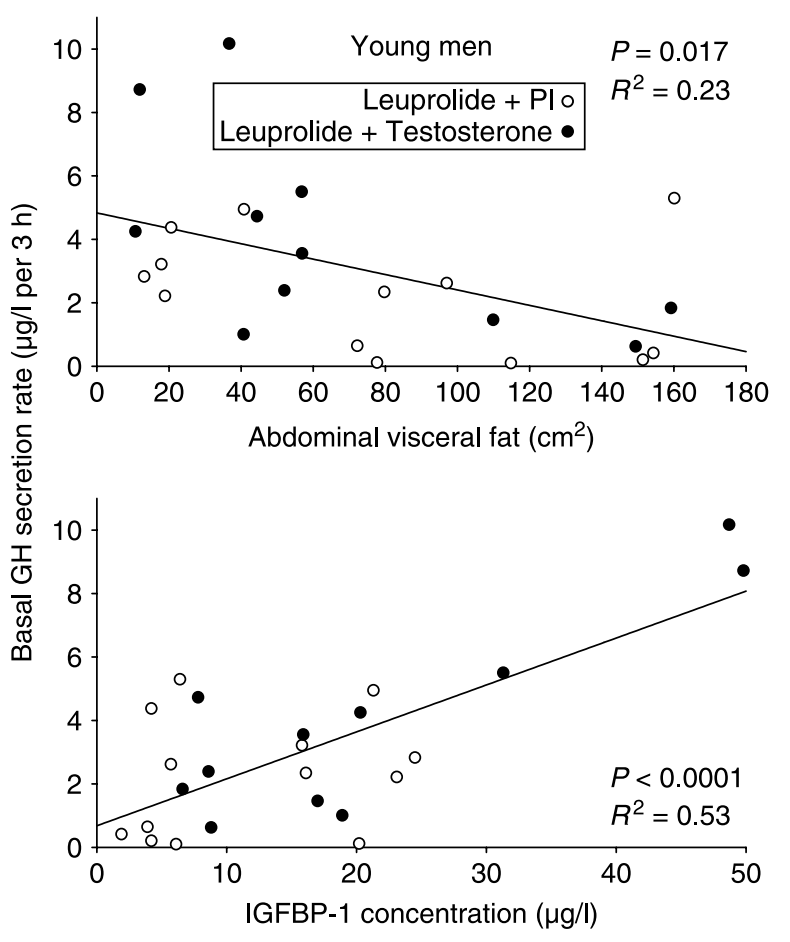

Figure 3 Regression of unstimulated basal (nonpulsatile) GH secretion rates on CT-estimated abdominal visceral fat (AVF) and serum IGFBP-1 concentrations in 24 young men treated with leuprolide and PI (open circles) or testosterone (closed circles). Two-tailed $P$ values are given with the correlation coefficients. 


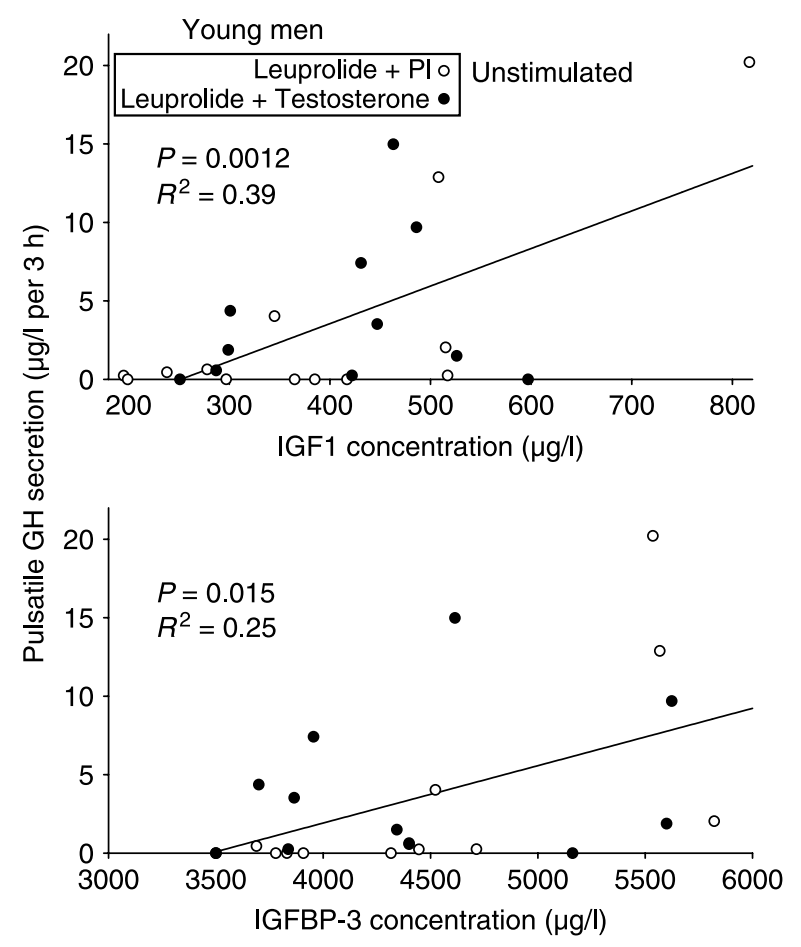

Figure 4 Positive relationships between unstimulated (salineinfused) pulsatile GH secretion and serum IGF1 (top) and IGFBP-3 (bottom) concentrations in 24 young men. Data are presented as described in Fig. 3.

strong effect of L-arginine/GHRP-2 over L-arginine/ GHRP $(P<0.001)$, but no effect of testosterone versus Pl addback $(P=0.79)$ and no interaction between secretagog and sex-steroid milieu $(P=0.49)$. The effect of L-arginine combined with GHRP-2 on pulsatile GH secretion was 2.0- and 2.7-fold that of L-arginine/ GHRH under low testosterone and high testosterone respectively. Unpaired statistical comparisons of pulsatile $\mathrm{GH}$ secretion $(\mu \mathrm{g} / \mathrm{l}$ per $3 \mathrm{~h})$ in the $\mathrm{Pl}$ versus testosterone-addback cohorts during the separate infusion of L-arginine/GHRH and L-arginine/GHRP-2 confirmed no differences due to testosterone/ $\mathrm{E}_{2}$ availability for either secretagog (Table 1).

Lack of statistical difference (at good statistical power, here $>95 \%$ ) between $\mathrm{Pl}$ and testosterone-addback responses permitted combining the data $(n=24$ subjects) statistically (21). Linear-regression analyses in the combined cohorts revealed that basal (nonpulsatile) GH secretion was inversely related to $\operatorname{AVF}\left(R^{2}=0.23\right.$, $P=0.017)$ and directly to IGFBP-1 concentrations $\left(R^{2}=0.53, P<0.0001\right.$; Fig. 3). Fasting unstimulated (saline-infused) pulsatile GH secretion correlated positively with IGF1 $\left(R^{2}=0.39, P=0.0012\right)$ and IGFBP-3 $\left(R^{2}=0.25, P=0.015\right)$ concentrations (Fig. 4). These outcomes point to potentially different modulation of basal versus pulsatile $\mathrm{GH}$ secretion in the unstimulated fasting state. These results remained significant at Bonferroni-restricted $P \leq 0.0167$ for assessment of the three IGF-related measures.

In the setting of secretagog infusions, regression analysis revealed a markedly negative effect of AVF $\left(R^{2}=0.35, \quad P=0.0024\right)$ on L-arginine/GHRH's stimulation of pulsatile GH secretion: Fig. 5 (top). By contrast, stimulation by L-arginine/GHRP-2 was not influenced by either age or AVF (both $P>0.10$ ). There was a strong trend toward IGF1 being a positive statistical determinant of pulsatile GH secretion driven by sequential L-arginine/GHRH infusion $\left(R^{2}=0.23, P=0.018\right.$; Fig. 5 (bottom)). On the other hand, none of IGF1, IGFBP-1, or IGFBP-3 concentrations, age, or AVF correlated with GH responses to L-arginine/GHRP-2. Accordingly, AVF is a major negative determinant of GHRH but not GHRP-2 action in this setting.

The waveform (time-dependent shape) of GH secretory bursts is estimated as the analytical mode of the secretory burst. Instead of being a measure of mass (amount of GH released), the mode denotes the time in min to attain maximal secretion after objectively estimated burst onset. By linear regression analysis and in the case of L-arginine/GHRH infusion only, $\operatorname{AVF}\left(R^{2}=0.26, P=0.011\right)$ correlated negatively, and IGFBP-1 positively $\left(R^{2}=0.27, P=0.0094\right)$, with GH secretory-burst mode (Fig. 6). Thus, the shape (waveform) of GH secretory events is influenced in

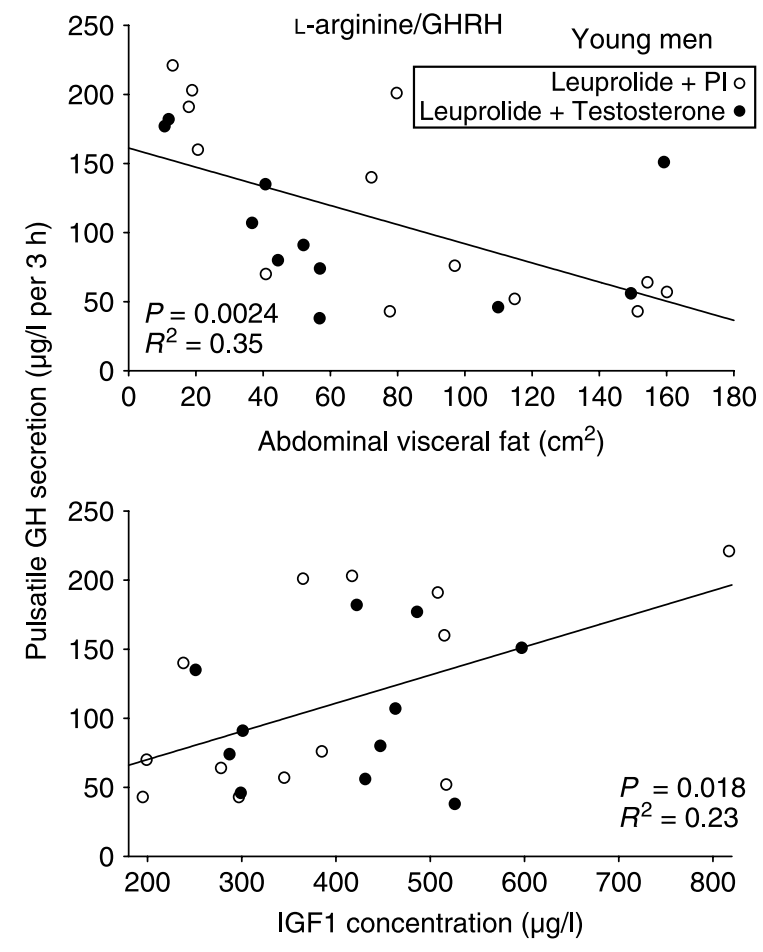

Figure 5 Efficacy of L-arginine/GHRH in stimulating pulsatile GH secretion correlates negatively with AVF (top) and positively with IGF1 concentrations (bottom; $n=24$ men, see Fig. 3). This was not true for L-arginine/GHRP-2. 


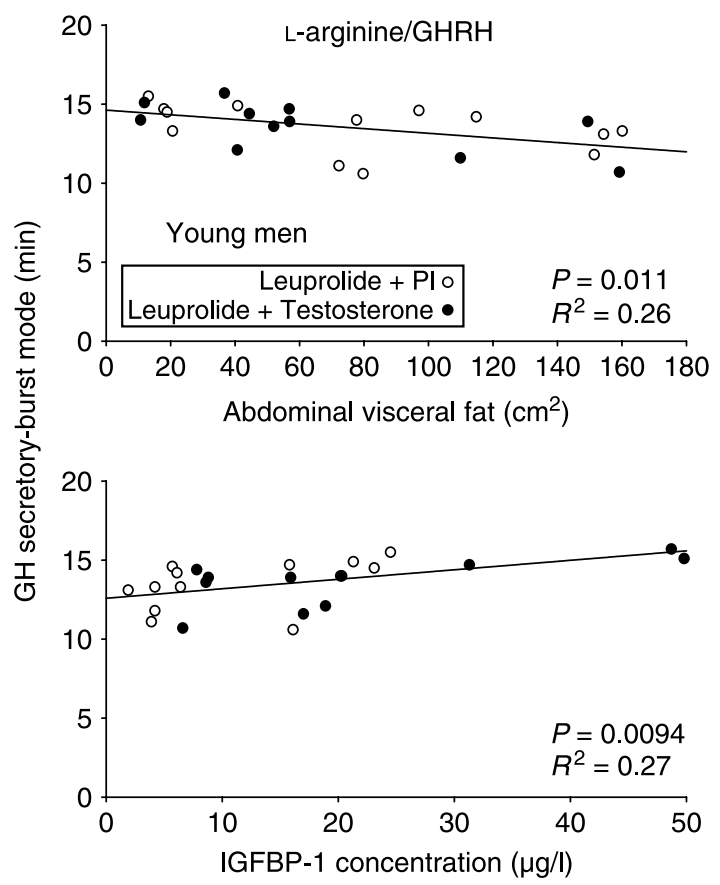

Figure 6 Impact of AVF (top) and IGFBP-1 concentrations (bottom) on L-arginine/GHRH-stimulated GH secretory-burst waveform.

The mode of the waveform is the time delay to maximal GH secretion. No such effects were evident for L-arginine/GHRP-2 stimulation.

some manner by AVF and IGF1, but not only when the secretagog is GHRH, thereby illustrating a further distinction in the mode of action of GHRH and GHRP-2.

\section{Discussion}

The present study affirms with high statistical power the $a$ priori hypothesis that $\mathrm{GH}$ responses to sequential L-arginine/GHRH and L-arginine/GHRP-2 infusions are resistant to marked short-term reduction of testosterone and $\mathrm{E}_{2}$ concentrations. The outcomes indicate that L-arginine infusion followed by either GHRH or GHRP-2 constitutes an effective secretagog combination in acutely (within 1 month) hypogonadal men. On the other hand, only sequential L-arginine/GHRP-2 also stimulated GH secretion independently of AVF and IGF markers. Thus, L-arginine/GHRP-2 may be a useful secretagog pair under clinical conditions in which hypogonadism is of recent onset and/or possible overweightness exists.

The gold-standard insulin-tolerance test has some practical limitations, thus prompting evaluation of other powerful GH-releasing agents, such as the combination of L-arginine and GHRP-2 assessed here. For clinical utility, efficacy (maximal response) has been the conventional endpoint. However, complete dose-response estimates would be required to quantify potency and sensitivity as well. Maximal hormone concentrations (height of peak) in general correlate directly with the mass of hormone secreted per burst (31). Thus, responses to the secretagogs utilized here yielded consistent inferences for secretory-burst mass (Tables and Figures) and maximal GH peak height (not shown).

The leuprolide-clamp paradigm also demonstrated that - independently of testosterone/ $\mathrm{E}_{2}$ status unstimulated basal (nonpulsatile) GH secretion was determined positively by IGFBP-1 concentrations and negatively by AVF, whereas unstimulated pulsatile GH secretion was related positively to both IGF1 and IGFBP-3 concentrations. IGF1 concentrations also represented a strongly positive predictor, and AVF a strongly negative predictor, of L-arginine/GHRH efficacy. In contradistinction, none of these factors influenced L-arginine/GHRP-2 stimulation in this cohort of 24 individuals. More studies will be required to assess the generality of this inference in other cohorts.

A parsimonious explanation for the observed nonsteroidal determinants of GHRH efficacy could be that high GHRH receptor-effector function enhances pulsatile GH output, which increases IGF1 and IGFBP-3 concentrations and decreases AVF. This scenario could explain both the positive association between pulsatile GH secretion and IGF1 and IGFBP-3 concentrations, and the negative association between pulsatile $\mathrm{GH}$ secretion and AVF. The precise reasons why GHRP does not exhibit the same multiple interdependencies with AVF- and IGF-related factors as GHRH are not so clear. A main difference from GHRH is that ghrelin/GHRP exerts hypothalamic effects required for synergism with GHRH (2).

Sex-steroid hormones in women regulate not only the amount of GH secreted in bursts, but also the waveform or time pattern of GH released within individual bursts (32). We could not detect testosterone/ $\mathrm{E}_{2}$ effects on secretory-burst shape in men. The mode represents a shape- or time-sensitive estimate of the delay to maximal secretion. This waveform term is independent of the amount (mass) of hormone secreted (33). However, AVF (negatively) and IGFBP-1 (positively) correlated with the time delay to maximal GH secretion under L-arginine/GHRH drive. Analyses using atomic-force microscopy indicate that GH-containing vesicles in pituitary cells must fuse with membrane pores to allow exocytosis (34). How AVF and IGFBP-1 modulate these processes is unknown.

Little is known about the regulation of basal (nonpulsatile) GH secretion (1). In the present study, this measure correlated positively with IGFBP-1 concentrations $\left(R^{2}=0.53, P<0.0001\right)$. The precise basis for this new association is not known. One plausible mechanism linking IGFBP-1 and basal GH secretion would be free IGF concentrations, which appear to inhibit GH secretion (35). 
Caveats include the relatively small cohort studied $(n=24)$, possible unknown effects of leuprolide per se, and the need to eventually extend paradigm duration.

In summary, L-arginine/GHRH and L-arginine/ GHRP-2 are robust stimulators of GH secretion in a short-term hypogonadal setting. L-arginine/GHRH efficacy is negatively determined by AVF and positively by IGF1 concentrations. No such effects were evident for L-arginine/GHRP-2 stimulation. AVF and IGFBP-1 are significant covariates of the waveform duration of L-arginine/GHRH (but not L-arginine/GHRP-2)-induced $\mathrm{GH}$ secretory bursts. The present outcomes delineate new distinctions between GHRH and GHRP actions, which may influence the choice of optimal secretagog in a particular clinical setting.

\section{Declaration of interest}

There is no conflict of interest that could be perceived as prejudicing the impartiality of the research reported.

\section{Funding}

Supported in part via the Center for Translational Science Activities (CTSA) Grant Number 1 UL 1 RR024150 to the Mayo Clinic and Foundation from the National Center for Research Resources (Rockville, MD, USA) and R01 NIA AG19695 from the National Institutes of Health (Bethesda, MD, USA).

\section{Acknowledgements}

We thank Donna Scott for support of manuscript preparation; Ashley Bryant for data analysis and graphics; the Mayo Immunochemical Laboratory for assay assistance; and the Mayo research nursing staff for implementing the protocol.

\section{References}

1 Giustina A \& Veldhuis JD. Pathophysiology of the neuroregulation of growth hormone secretion in experimental animals and the human. Endocrine Reviews 199819 717-797.

2 Veldhuis JD, Roemmich JN, Richmond EJ \& Bowers CY. Somatotropic and gonadotropic axes linkages in infancy, childhood, and the puberty-adult transition. Endocrine Reviews $2006 \mathbf{2 7}$ $101-140$.

3 Weltman A, Weltman JY, Hartman ML, Abbott RD, Rogol AD, Evans WS \& Veldhuis JD. Relationship between age, percentage body fat, fitness, and 24-hour growth hormone release in healthy young adults: effects of gender. Journal of Clinical Endocrinology and Metabolism 199478 543-548.

4 Vahl N, Jorgensen JO, Skjaerback C, Veldhuis JD, Orskov H \& Christiansen J. Abdominal adiposity rather than age and sex predicts the mass and patterned regularity of growth hormone secretion in mid-life healthy adults. American Journal of Physiology 1997272 E1108-E1116.

5 Veldhuis JD, Erickson D, Mielke K, Farhy LS, Keenan DM \& Bowers CY. Distinctive inhibitory mechanisms of age and relative visceral adiposity on GH secretion in pre- and postmenopausal women studied under a hypogonadal clamp. Journal of Clinical Endocrinology and Metabolism 200590 6006-6013.

6 Chalew SA, Udoff LC, Hanukoglu A, Bistritzer T, Armour KM \& Kowarski AA. The effect of testosterone therapy on spontaneous growth hormone secretion in boys with constitutional delay. American Journal of Diseases of Children 1988 142 1345-1348.

7 Loche S, Colao A, Cappa M, Bellone J, Aimaretti G, Farello G, Faedda A, Lombardi G, Deghenghi R \& Ghigo E. The growth hormone response to hexarelin in children: reproducibility and effect of sex steroids. Journal of Clinical Endocrinology and Metabolism 199782 861-864.

8 Martin LG, Clark W \& Connor TB. The growth hormone secretion enhanced by androgens. Journal of Clinical Endocrinology and Metabolism 196828 425-431.

9 Giustina A, Scalvini T, Tassi C, Desenzani P, Poiesi C, Wehrenberg WB, Rogol A \& Veldhuis JD. Maturation of the regulation of growth hormone secretion in young males with hypogonadotropic hypogonadism pharmacologically exposed to progressive increments in serum testosterone. Journal of Clinical Endocrinology and Metabolism 199782 1210-1219.

10 Devesa J, Lois N, Arce V, Diaz MJ, Lima L \& Tresguerres JA. The role of sexual steroids in the modulation of growth hormone (GH) secretion in humans. Journal of Steroid Biochemistry and Molecular Biology 199140 165-173.

11 Fryburg DA, Weltman A, Jahn LA, Weltman JY, Samolijik E \& Veldhuis JD. Short-term modulation of the androgen milieu alters pulsatile but not exercise or GHRH-stimulated GH secretion in healthy men. Journal of Clinical Endocrinology and Metabolism 1997 82 3710-3719.

12 Ghigo E, Arvat E, Valente F, Nicolosi M, Boffano GM, Procopio M, Bellone J, Maccario M, Mazza E \& Camanni F. Arginine reinstates the somatotrope responsiveness to intermittent growth hormone-releasing hormone administration in normal adults. Neuroendocrinology 199154 291-294.

13 Alba-Roth J, Muller OA, Schopohl J \& Von Werder K. Arginine stimulates growth hormone secretion by suppressing endogenous somatostatin secretion. Journal of Clinical Endocrinology and Metabolism 198867 1186-1189.

14 Vale WW, Vaughan J, Yamamoto G, Spiess J \& Rivier J. Effects of synthetic human pancreatic (tumor) GH releasing factor and somatostatin, triiodothyronine and dexamethasone on GH secretion in vitro. Endocrinology 1983112 1553-1555.

15 Fairhall KM, Mynett A \& Robinson IC. Central effects of growth hormone-releasing hexapeptide (GHRP-6) on growth hormone release are inhibited by central somatostatin action. Journal of Endocrinology $199514 \mathbf{4 5 5 5 - 5 6 0 .}$

16 Veldhuis JD \& Bowers CY. Determinants of GH-releasing hormone and GH-releasing peptide synergy in men. American Journal of Physiology. Endocrinology and Metabolism 20095 E1085-E1092.

17 Anderson SM, Shah N, Evans WS, Patrie JT, Bowers CY \& Veldhuis JD. Short-term estradiol supplementation augments growth hormone $(\mathrm{GH})$ secretory responsiveness to dose-varying GH-releasing peptide infusions in healthy postmenopausal women. Journal of Clinical Endocrinology and Metabolism 200186 $551-560$.

18 Veldhuis JD, Evans WS \& Bowers CY. Estradiol supplementation enhances submaximal feedforward drive of growth hormone (GH) secretion by recombinant human GH-releasing hormone1,44-amide in a putatively somatostatin-withdrawn milieu. Journal of Clinical Endocrinology and Metabolism $2003 \mathbf{8 8}$ 5484-5489.

19 Takahashi PY, Votruba P, Abu-Rub M, Mielke K \& Veldhuis JD. Age attenuates testosterone secretion driven by amplitude-varying pulses of recombinant human luteinizing hormone during acute gonadotrope inhibition in healthy men. Journal of Clinical Endocrinology and Metabolism 200792 3626-3632.

20 Cosma M, Bailey JN, Miles JM, Bowers CY \& Veldhuis JD. Pituitary and/or peripheral estrogen-receptor alpha $(\mathrm{ER} \alpha)$ regulates FSH secretion whereas central pathways direct $\mathrm{GH}$ and prolactin secretion in postmenopausal women. Journal of Clinical Endocrinology and Metabolism 200893 951-958.

21 Fisher LD \& van Belle G. Descriptive statistics. In Biostatistics: a Methodology for the Health Sciences, pp 58-74. New York: John Wiley \& Sons, 1996. 
22 Hobbs CJ, Plymate SR, Rosen CJ \& Adler RA. Testosterone administration increases insulin-like growth factor-I levels in normal men. Journal of Clinical Endocrinology and Metabolism 1993 77 776-779.

23 Bondanelli M, Ambrosio MR, Margutti A, Franceschetti P, Zatelli MC \& degli Uberti EC. Activation of the somatotropic axis by testosterone in adult men: evidence for a role of hypothalamic growth hormone-releasing hormone. Neuroendocrinology 200377 380-387.

24 Gentili A, Mulligan T, Godschalk M, Clore J, Patrie J, Iranmanesh A \& Veldhuis JD. Unequal impact of short-term testosterone repletion on the somatotropic axis of young and older men. Journal of Clinical Endocrinology and Metabolism $200287825-834$.

25 Veldhuis JD, Keenan DM, Mielke K, Miles JM \& Bowers CY. Testosterone supplementation in healthy older men drives $\mathrm{GH}$ and IGF1 secretion without potentiating peptidyl secretagogue efficacy. European Journal of Endocrinology 2005153 577-586.

26 Veldhuis JD, Anderson SM, Iranmanesh A \& Bowers CY. Testosterone blunts feedback inhibition of $\mathrm{GH}$ secretion by experimentally elevated IGF1 concentrations. Journal of Clinical Endocrinology and Metabolism 200590 1613-1617.

27 Chattopadhyay S, Veldhuis JD \& Keenan DM. Probabilistic recovery of pulsatile, secretory and kinetic structure: an alternating discrete and continuous schema. Quarterly of Applied Mathematics 200866 401-421.

28 Keenan DM, Roelfsema F, Biermasz N \& Veldhuis JD. Physiological control of pituitary hormone secretory-burst mass, frequency and waveform: a statistical formulation and analysis. American Journal of Physiology 2003285 R664-R673.

29 Faria ACS, Veldhuis JD, Thorner MO \& Vance ML. Half-time of endogenous growth hormone $(\mathrm{GH})$ disappearance in normal man after stimulation of GH secretion by GH-releasing hormone and suppression with somatostatin. Journal of Clinical Endocrinology and Metabolism 198968 535-541.

30 Akaike H. A new look at the statistical model identification. IEEE Transactions on Automatic Control 197419 716-723.

31 Veldhuis JD, Lassiter AB \& Johnson ML. Operating behavior of dual or multiple endocrine pulse generators. American Journal of Physiology 1990259 E351-E361.

32 Veldhuis JD, Keenan DM \& Bowers CY. Estimation of the size and shape of GH secretory bursts in healthy women using a physiological estradiol clamp and variable-waveform deconvolution model. American Journal of Physiology. Regulatory, Integrative and Comparative Physiology 2007293 R1013-R1021.

33 Veldhuis JD, Keenan DM \& Pincus SM. Motivations and methods for analyzing pulsatile hormone secretion. Endocrine Reviews 2008 29 823-864.

34 Cho SJ, Jeftinija K, Glavaski A, Jeftinija S, Jena BP \& Anderson LL. Structure and dynamics of the fusion pores in live GH-secreting cells revealed using atomic force microscopy. Endocrinology 2002 143 1144-1148.

35 Chen JW, Hojlund K, Beck-Nielsen H, Sandahl CJ, Orskov H \& Frystyk J. Free rather than total circulating insulin-like growth factor-I determines the feedback on growth hormone release in normal subjects. Journal of Clinical Endocrinology and Metabolism $200590366-371$.

Received 24 April 2009

Accepted 12 May 2009 